\title{
DECLARACIÓN DE SAN JOSÉ DE COSTA RICA
}

Los congresistas asistentes al IV Congreso Iberoamericano de Derecho Sanitario y II Seminario Internacional de Derecho Sanitario, reunidos en la ciudad de San José de Costa Rica los días 18, 19 y 20 de agosto de 2014, al cabo de sus deliberaciones DECLARAN QUE:

1) Dicho congreso se desarrolló cumpliendo estrictamente el programa académico diseñado, con una alta participación de público constituido por abogados, médicos, sociólogos, trabajadores sociales, economistas y otros profesionales vinculados a la salud, y con elevado nivel científico y académico de quienes tuvieron a su cargo la exposición de los distintos temas, presentaron sus comunicaciones y posters en forma voluntaria y, en forma también espontánea, expusieron sus ideas y formularon preguntas y sugerencias a los panelistas.

2) La reafirmación de que la salud tiene múltiples determinantes sociales y que el Derecho cumple su papel de normalizar, regular y garantizar el derecho a la salud de las personas, al amparo de los principios del Estado de Derecho y de la normativa internacional en la materia.

3) El acceso universal a una cobertura de salud pública y de calidad constituye uno los objetivos estratégicos que la Red lberoamericana de Derecho Sanitario tiene como pilar fundamental.

4) El papel del Derecho es el de garantizar sistemas de salud garantistas y eficientes en el marco del concepto de Estado de Bienestar Social, así como los distintos subsistemas (salud mental, discapacidad, grupos de riesgo etc.) que deben perseguir la mejora constante en los indicadores de salud.

5) La excesiva judicialización de la salud se revela, en la actualidad, como uno de los grandes problemas de la salud pública que sólo a través del Derecho y sus operadores pude llegar a superarse, a través de mecanismos alternativos, manteniendo siempre la garantía jurisdiccional propia del Estado de Derecho.

6) La excesiva tecnologización de los tratamientos médicos, a la vez que deshumaniza la atención de la salud, contribuye al fortalecimiento de los empresarios de la medicina, desplazando al ciudadano del centro de la atención de los sistemas sanitario. 
7) Las investigaciones biomédicas en seres humanos deben respetar a la persona en cuanto objeto de investigación. El avance científico no puede, en ningún caso, implicar la afectación de la dignidad del ser humano.

8) Los medios de comunicación deben cumplir su rol de información, ajustándose a las normas jurídicas y éticas que limitan el ejercicio de esa profesión, guiados por el interés público y no por el 'morbo' público, y respetando, en todo caso, el derecho a la intimidad, a la imagen y a la confidencialidad de los datos personales, reconocido por las normas del más alto nivel jerárquico y por la conciencia jurídica universal.

9) La formación de los profesionales de salud debe, ante todo, garantizar el compromiso de conciencia de los mismos con la sociedad, con una visión humanista, solidaria e inclusiva, y con el más elevado nivel científico y técnico posible que asegure la calidad de las prestaciones.

10) Finalmente, exhortan a los miembros de la Red a guiar sus acciones en salud conforme a los principios que forman parte de la presente declaración, así como a propiciar su efectivización y difusión en cada uno de los países que la componen, formulando la más amplia convocatoria de todos quienes compartan los postulados enunciados.

San José de Costa Rica, 20 de agosto de 2014. IV Congreso Iberoamericano de Derecho Sanitario 